\title{
Automation and Scale Up of Somatic Embryogenesis for Commercial Plant Production, With Emphasis on Conifers
}

\author{
Ulrika Egertsdotter ${ }^{1,2 *}$, Iftikhar Ahmad ${ }^{1}$ and David Clapham ${ }^{3}$ \\ ${ }^{1}$ Department of Forest Genetics and Plant Physiology, Umeå Plant Science Centre, Swedish University of Agricultural \\ Sciences, Umeå, Sweden, ${ }^{2}$ G.W. Woodruff School of Mechanical Engineering, Georgia Institute of Technology, Atlanta, GA, \\ United States, ${ }^{3}$ Department of Plant Biology, Uppsala BioCenter, Swedish University of Agricultural Sciences, Uppsala, \\ Sweden
}

OPEN ACCESS

Edited by:

Paloma Moncaleán, Neiker Tecnalia, Spain

Reviewed by:

Jan Max Bonga,

Natural Resources Canada, Canadian

Forest Service, Canada

Elena Corredoira,

Instituto de Investigaciones Agrobiológicas de Galicia (IIAG), Spain

*Correspondence:

Ulrika Egertsdotter

Ulrika.Egertsdotter@s/u.se

Specialty section:

This article was submitted to Plant Development and EvoDevo, a section of the journal

Frontiers in Plant Science

Received: 13 November 2018

Accepted: 23 January 2019

Published: 18 February 2019

Citation:

Egertsdotter U, Ahmad I and Clapham D (2019) Automation and

Scale Up of Somatic Embryogenesis for Commercial Plant Production, With

Emphasis on Conifers.

Front. Plant Sci. 10:109. doi: 10.3389/fpls.2019.00109
For large scale production of clonal plants, somatic embryogenesis (SE) has many advantages over other clonal propagation methods such as the rooting of cuttings. In particular, the SE process is more suited to scale up and automation, thereby reducing labor costs and increasing the reliability of the production process. Furthermore, the plants resulting from SE closely resemble those from seeds, as somatic embryos, like zygotic (seed) embryos, develop with good connection between root and shoot, and without the plagiotropism often associated with propagation by cuttings. For practical purposes in breeding programs and for deployment of elite clones, it is valuable that a virtually unlimited number of SE plants can be generated from one original seed embryo; and SE cultures (clones) can be cryostored for at least 20 years, allowing long-term testing of clones. To date, there has however been limited use of SE for large-scale plant production mainly because without automation it is labor-intensive. Development of automation is particularly attractive in countries with high labor costs, where conifer forestry is often of great economic importance. Various approaches for automating SE processes are under investigation and the progress is reviewed here, with emphasis on conifers. These approaches include simplification of culture routines with preference for liquid rather than solid cultures, use of robotics and automation for the harvest of selected individual mature embryos, followed by automated handling of germination and subsequent planting. Different approaches to handle the processes of somatic embryogenesis in conifers are outlined below, followed by an update on efforts to automate the different steps, which are nearing an operational stage.

Keywords: somatic embryogenesis, conifer, automation, scale up, bioreactors

\section{INTRODUCTION TO SOMATIC EMBRYOGENESIS FOR LARGE-SCALE PLANT PRODUCTION}

Somatic embryogenesis is a desirable method for clonal propagation of plants as it offers many biological and practical advantages. Biologically, the somatic embryo progresses through a developmental process much like its zygotic counterparts (Pullman et al., 2003; Cairney and Pullman, 2007). Development of root and shoot meristems 
results in good connection between root and shoot in the resulting plant, avoiding the issues with plagiotropic growth, and adventitious root formation that are concerns with propagation by cuttings. Furthermore, the opportunity to keep embryogenic cell lines for prolonged periods in cryostorage allows for fieldtesting before selection of production cell lines (Park et al., 2014). For commercial plant production, especially the earliest in vitro phase of embryo multiplication offers opportunities to scale up for bulk production of desirable genotypes by using liquid culture medium.

Various private companies have estimated the economics of in vitro plant production. One of the few public estimates completed already in the mid-1990s showed that about $50 \%$ of the production costs for in vitro plants stem from labor (Cervelli and Senaratna, 1995). As labor costs of the various steps of the process are high, cost components could change dramatically by for example automating SE multiplication in bioreactors (Cervelli and Senaratna, 1995; Heyerdahl et al., 1995). Still, more than 20 years later, reviews point to the high cost of labor as prohibitive for large scale plant production in the absence of automation (Lelu-Walter et al., 2013). This applies particularly to conifers, the most important forest species in the northern hemisphere.

Somatic embryos are induced directly from different parts of the plant depending on species or indirectly from undifferentiated callus tissue (Halperin, 1995; Yeung, 1995; Fehér et al., 2003). Differences in the pathway of zygotic embryogenesis between angiosperms and conifers, as outlined in Figure 1, are reflected in the corresponding pathways of somatic embryogenesis. The basic laboratory processes supporting somatic embryogenesis are, however, largely similar across species in terms of the steps of the in vitro processes required to produce a plant: after the first step of initiating the somatic embryos from the explant, follow the cultural handling steps of multiplication, embryo development, germination, and plant formation after transfer to ex vitro for plant establishment in compost (Figure 2). In the present review, the somatic embryogenesis processes from early stage somatic embryos, to planting ex vitro of the germinated embryos, will be discussed. In an earlier review on the same topic (Ibaraki and Kurata, 2001) that focused on angiosperm SE, the main processes outlined were (1) induction, (2) maintenance of embryogenic cultures and (3) development of embryos. In this present review, the focus will be on automation and scale up of the various steps required to produce a plant from a somatic embryo in conifer species, emphasizing progress since 2001 that has been accomplished particularly with the economically important Norway spruce (Picea abies L. Karst).

To date, the majority of somatic embryo cultures in conifer species have been induced from seed embryos. To characterize and score the resulting trees from the SE cell lines initiated from a seed, most commercial entities are deploying SE plants into field testing whilst keeping the corresponding SE cultures in cryogenic storage. Another approach to clonal mass propagation, at the same time integrating somatic embryogenesis into the traditional breeding program, is via "family forestry" (Rosvall et al., 1998; Lindgren, 2008): the mass propagation of untested individuals or clones from tested families, i.e., families that have already been tested in the course of the breeding program. Planting with a mixture of 25 clones from six parents of tested families at each stand removes the dangers of excessive genetic uniformity associated with single clones, while exploiting the full genetic gains at the family level and avoiding the considerable expense and delay associated with effective clonal testing (Lindgren, 2008). In Scandinavia trees must be at least 10 years old before selection for growth characters is meaningful, owing to poor juvenile/mature correlations; but this situation may change with the development of mass genomic selection (e.g., Iwata et al., 2011; Beaulieu et al., 2014)

As SE plant production from at least Norway spruce may become a reality in the near future owing to the recent technological developments, the possible impact from integration of SE plants as parts of clonal forestry operation into Swedish forestry was recently examined from different perspectives. The benefits in terms of genetic gains and the potential risks of clonal forestry were reviewed by Wu (2018), and effects of clonal forestry on genetic diversity in wild and domesticated stands of forest trees by Ingvarsson and Dahlberg (2018). Furthermore, the potential inherent risks from the SE process were examined by Egertsdotter (2018). Taken together, it can be concluded that with sufficient numbers of clones in production, that are replaced at certain intervals, SE plants can soon become a cost-effective, accepted and viable contribution to Swedish forestry operations provided that the required automation becomes reliably available.

\section{OVERVIEW OF SOMATIC EMBRYOGENESIS IN IN VITRO DEVELOPMENTAL PROCESSES}

\section{Initiation}

The starting operation of initiating an SE-culture is typically associated with detailed dissection of certain cell-layers or structures of the responsive tissue in an initial explant. There are no known efforts directed toward automation of this process. In conifers, where the common source of initial explant is the zygotic embryo, extraction of the female megagametophyte (FMG), and even extraction of the ZE from within the FMG, are required for success. With the diversity of seed sizes and shapes, and the sensitivity of the target tissue (the embryo), this process has not been an attractive target for automation. Also, for many angiosperms where the initial (vegetative) explant is accessible and plentiful, other parts of the SE process are more relevant for automation.

\section{Multiplication}

After establishment from the initial explant, the conifer SE culture is maintained or proliferated by repeated subculture into fresh media promoting multiplication. Auxins and cytokinins are common plant growth regulators (PGRs) that enable proliferation of early stage embryos (e.g., von Arnold and Clapham, 2008) and the nature of the nitrogen source is important (e.g., Carlsson et al., 2017). Liquid suspension cultures of conifers can multiply at higher rates and with less aggregation 
A

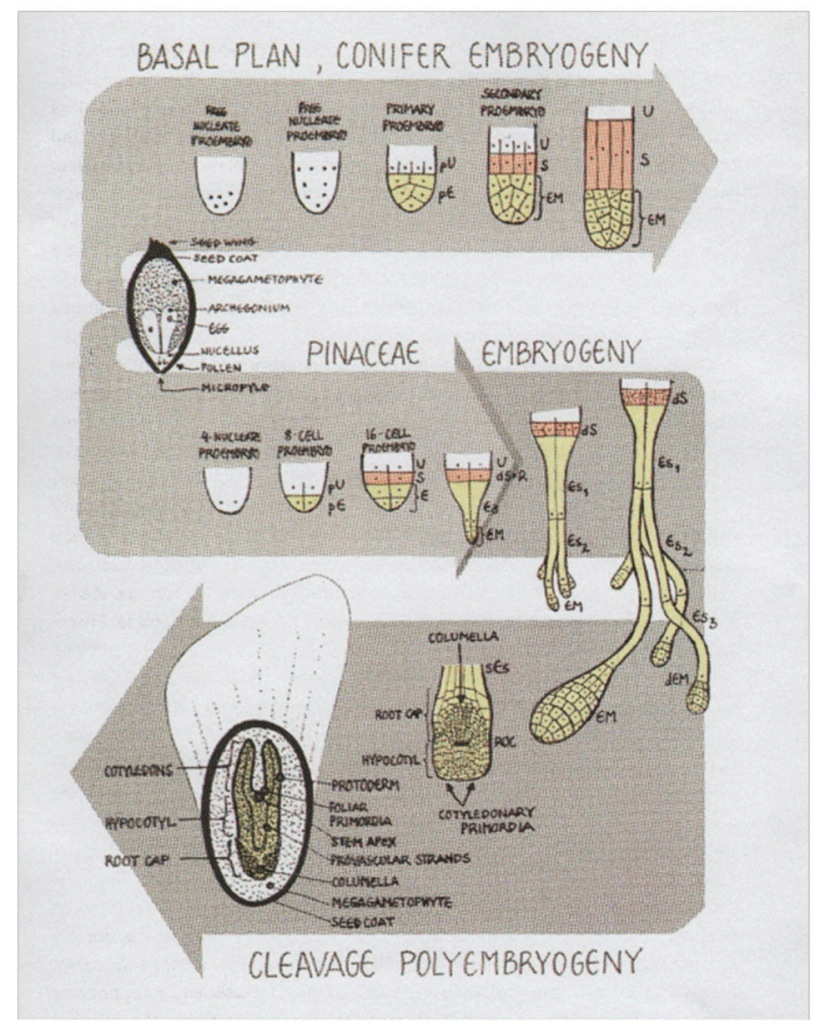

B

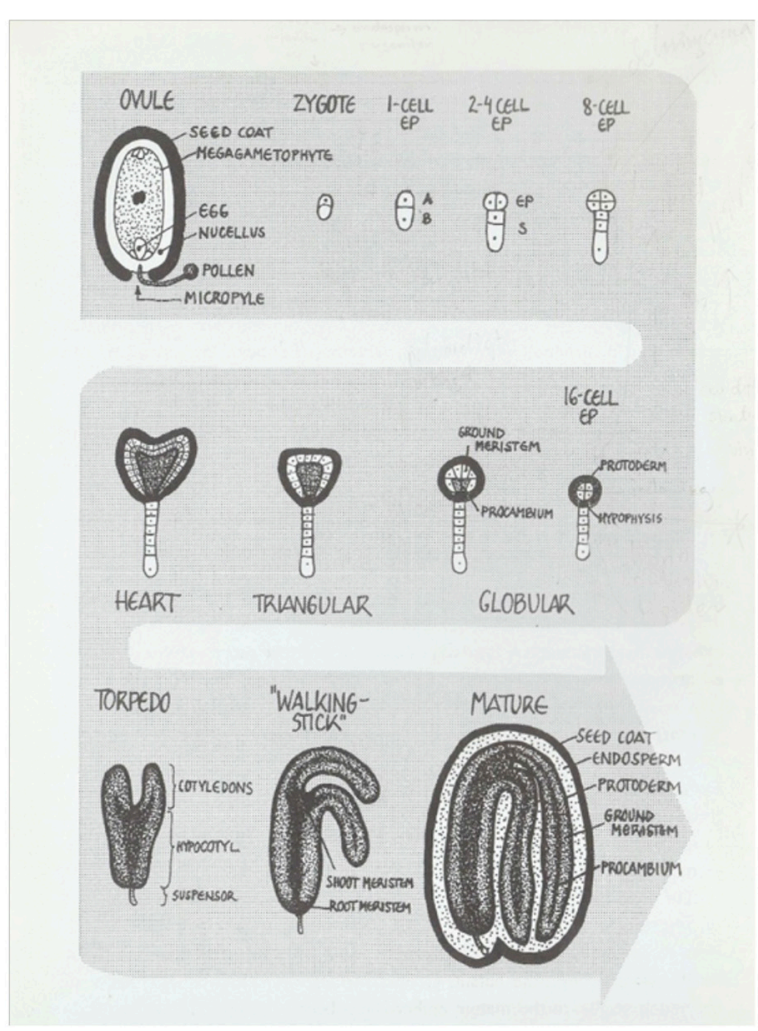

FIGURE 1 | Zygotic embryo development in gymnosperms and angiosperms differs in some major aspects. (A) Early stages of conifer embryo development. The conifer zygote results from a single fertilization event. At the beginning of embryogenesis, there are free nuclear stages followed by a pro-embryo stage. Main characteristics of conifer embryo development are the polyembryogenic features of some conifer species where the zygotic embryos to different degrees proceed through a process of embryo-cleavage that results in multiple embryos that are eventually eliminated by programmed cell death. (B) In angiosperm embryo development the sporophytic generation is initiated by a double fertilization event resulting in one embryo. (A) pU, primary upper tier; $p E$, primary embryonal tier; $\mathrm{U}$, upper tier; S, suspensor tier; EM, embryo mass; dS, R: dysfunctional suspensor tier; Es, embryonal suspensor tier; dEM, degenerating embryo mass; ROC, root organization center; sEs, secondary embryonal suspensor cells. (B) A, apical cell; B, basal cell; EP, embryo proper; S, suspensor. Figure adapted from Egertsdotter (1996).

than those on solid medium (Von Arnold et al., 2002) and are consequently preferred for the multiplication phase. Agitation of the liquid medium helps to break up the PEM tissue into smaller aggregates of PEMs that can multiply without hindrance from connected tissue (Egertsdotter and von Arnold, 1998). Multiplication in liquid medium also enables scale up in bioreactors and automation of the process. However, for the subsequent maturation, full immersion in liquid medium does not work effectively, as discussed below. The time in the multiplication phase is determined by the rate of multiplication of the particular species and cell line, and the target number of plants to be produced. In Norway spruce, the composition of the multiplying culture in terms of proportion of early stage somatic embryos, or stages of the proembryogenic masses (PEMs) present that can respond to the maturation treatment and continue to the next developmental stage, has been carefully investigated at the cellular level (Filonova et al., 2000a,b). The proportion of PEMs responsive to maturation treatment greatly influences the yield from conifer SE cultures. In angiosperms, the same diversity of developmental stages of early stage multiplying embryos can be observed. Owing to the morphology of the somatic embryos, fractionation of sizes by sieving the cultures has been shown to support synchronization in embryo cultures in angiosperms, e.g., in Daucus carota L. (Fujimura and Komamine, 1979), Citrus sinensis (L.) Osbeck (Souza et al., 2011), and Fraxinus angustifolia Vahl (Tonon et al., 2001). As the early stage embryos of a conifer PEM culture are composed of tightly associated clusters of embryos forming a web of embryonic tissue, fractionation and sieving of different stages of conifer somatic embryos are not effective.

\section{Maturation}

In conifers, maturation of somatic embryos is triggered by a change in the culture medium composition where PGRs and carbohydrates are key components (e.g., von Arnold and Clapham, 2008). Typically, maturation starts on a medium without auxin and cytokinin but supplied with abscisic acid, a key regulator (Tikkinen et al., 2018a). Maturation usually takes at least 4 to 6 weeks depending on species and cell line. Embryos mature asynchronously, partly reflecting their previous developmental history. Through dispersion and by addition of suitable carbohydrates, synchronization of mature embryos can 


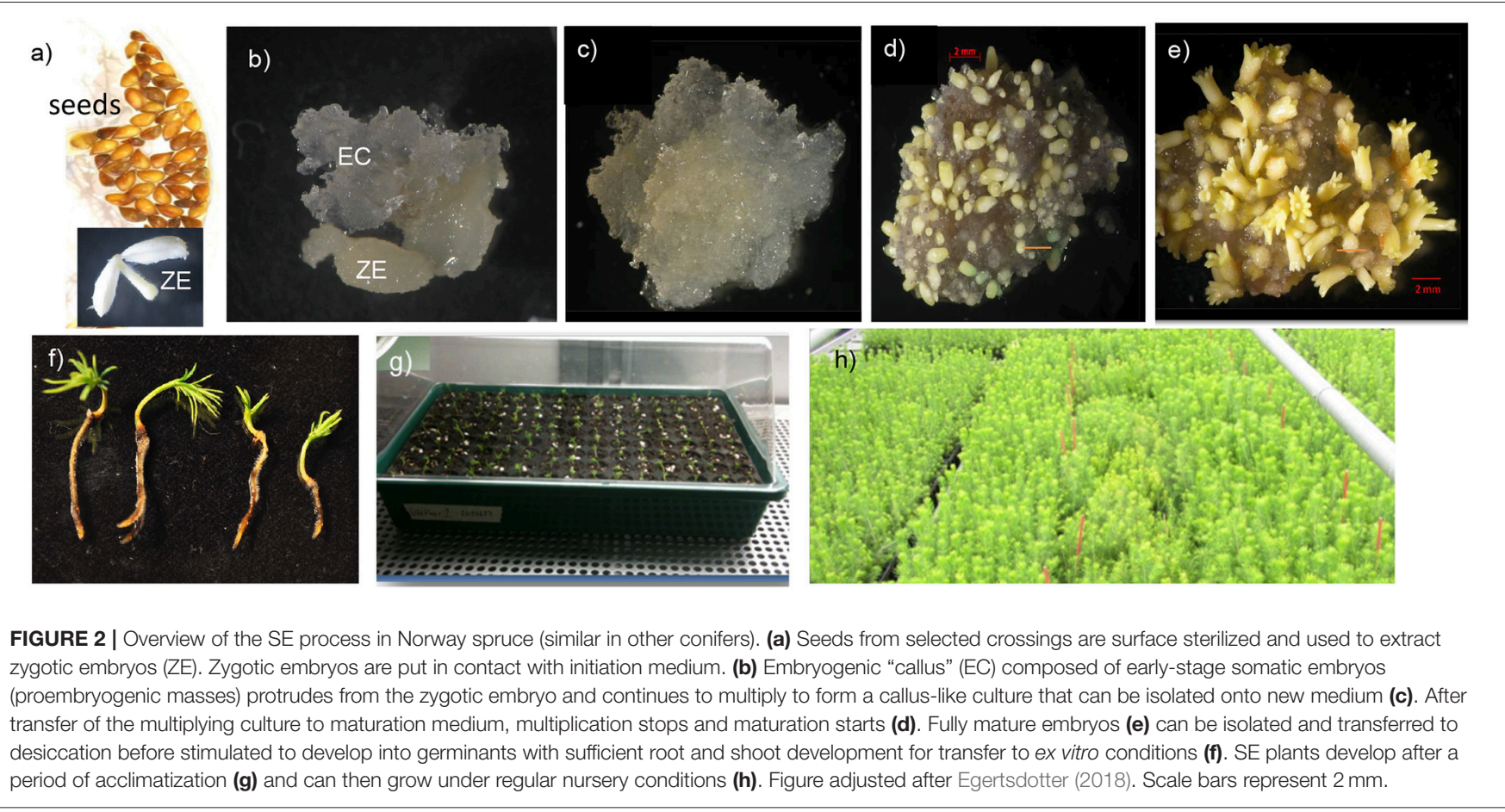

be increased (Egertsdotter and Clapham, 2011). To date, most conifer SE cultures are matured placed directly in contact with solidified medium or on a filter paper on the solid medium surface if plated out from a suspension culture. Efforts to produce mature embryos continuously immersed in liquid medium in bioreactors or suspension flasks have not encouraged large-scale production except for particular cell lines of white spruce, Picea glauca (Moench) Voss (Hakman and von Arnold, 1988) and Norway spruce (Gorbatenko and Hakman, 2001). Maturation on solid medium in plates or other vessels allows formation of mature embryos from the PEMs of many cell lines, and is still the most commonly used method for embryo maturation. However, embryo maturation can also be obtained in temporary immersion bioreactors where the embryos rest on a solid support and are fed intermittently with maturation medium (Businge et al., 2017; Mamun et al., 2018). When maturation is complete, embryos are often subjected to a desiccation treatment in preparation for storage and germination. Automated processes for maturation based on a solid support in temporary immersion bioreactors have been described for various conifer species and are discussed below.

\section{Germination and Plant Formation}

Mature embryos are typically desiccated under high relative humidity. Desiccation for extended times at lower temperatures was recently shown to give increased rates of germination (Tikkinen et al., 2018b). The conditions for successful desiccation allowing for long-term storage of mature embryos have been carefully investigated (Attree and Fowke, 1993 and references therein). The storage can help to accumulate embryos from recalcitrant cell lines and to adapt the germination time to other nursery operations. But if controlled environments are available, established plants, inwintered as appropriate, can be stored according to conventional nursery practices as widely applied for Norway spruce and Scots pine (Pinus sylvestris) in Sweden (Ersson, 2016).

Germination is started by placing the mature (desiccated) embryo in contact with germination medium. Most commonly, this is gelled germination medium in a petri plate, but efforts have been made to supply liquid germination medium to mature embryos placed on a porous material for the purpose of scaling up the process (discussed below). Darkness or dim red light are often recommended for the first 2 to 3 weeks of germination (Kvaalen and Appelgren, 1999) which often proceeds for 6 weeks or longer (Dobrowolska et al., 2017); but recently, appropriate cold pre-treatments were shown to improve germination rates after only 1 week of in vitro germination (Tikkinen et al., 2018a,b). When sufficient root and shoot have developed, the germinants are planted in compost and gradually acclimatized to suitable ex vitro conditions based on experience with seedlings of various provenances grown in controlled environments; for example, continuous light at $20^{\circ} \mathrm{C}$ for Picea abies, long days and short nights (nights at reduced temperature) for boreal Pinus species (Ekberg et al., 1979; Högberg et al., 2001).

\section{AUTOMATION OF DIFFERENT STEPS OF THE SE PROCESS \\ Automation and Bioreactors for Scale Up of Embryo Production}

The multiplication step, possible in liquid medium with most species, offers the choice of scale up in bioreactors and thereby 
automation of the process. The tendency in the laboratory has been for all steps of the process to take place in petri plates. Automated production of the petri plates with solid medium can be applied to reduce labor, but transfer of the SE cultures between plates is still manual even in larger scale operations (e.g., KF Bioplants, Pvt, Ltd.,Pune, India). For multiplication, there are options for scale up by culture in liquid medium in suspension flasks or different types of bioreactors (Mamun et al., 2015). Liquid medium has many advantages in terms of providing the propagules better and more even access to medium components as well as facilitating automation. One major down side is that liquid-based cultures are more prone to contamination than those on solid medium, which is especially daunting for largescale bioreactor cultures.

The conifer SE processes differ in some ways from the angiosperm SE processes. Importantly for scale up processes in bioreactors, conifers appear to prefer a solid substrate to support directional growth of the most developmentally advanced PEMs (Sun et al., 2010). A polarized early stage PEM structure which represents the more developed early stages of somatic embryos is most likely to respond to the maturation treatment (Sun et al., 2011). Therefore, temporary immersion bioreactors providing solid support for culture growth by the mesh constituting the bottom of the bioreactor insert promotes directional growth of PEMs and formation of polarized early stage embryos and can thus have advantages over other types of bioreactors based on complete immersion and agitation of the culture.

Temporary immersion bioreactors can provide the required conditions for both multiplication and maturation of conifer somatic embryo development. Such bioreactors can be used for the shoot multiplication of hardwood trees (Businge et al., 2017) and probably for the germination of conifer somatic embryos. The bioreactor can have separate containers for plant material and culture medium, allowing for easy and safe exchange of culture medium without disturbing the culture (Figure 3); or, the culture medium is held within the same container as the culture, separated by a screen, e.g., RITA bioreactor types (VITROPIC). For SE cultures of conifers, multiplication and maturation can occur sequentially in the same bioreactor without disturbing the culture. Bioreactors are started with PEMs cultures grown as suspension cultures, or solid cultures that are dispersed at the start of the bioreactor culture (see details below).

Multiplication of conifer PEMs results in clumps of connected tissue where the interior parts become dormant over time. To optimize multiplication rates and development of PEMs, it is beneficial to create a thin layer of PEMs where a larger number of early stage embryos are exposed to culture medium. Such growth conditions can be created by dispersing the clumps of PEMs into a suspension and distributing the suspension onto a supportive medium surface (Aidun, 2015; Aidun and Egertsdotter, 2015). Increasing the proportion of active PEMs also increases the number of mature embryos that can be formed and thereby the conversion rate of mature embryos from PEMs. This procedure is particularly useful for culture in bioreactors based on liquid culture medium (Mamun et al., 2015). However, to date the successful use of temporary immersion bioreactors has been reported only for Abies nordmanniana (Businge et al., 2017) and

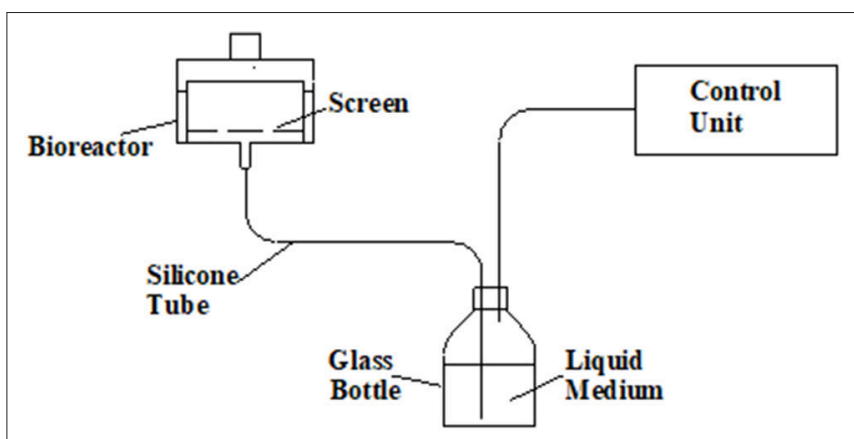

FIGURE 3 | Temporary immersion bioreactor model with the liquid medium separated from the culture container. Feeding is controlled by a digital timer through a solenoid valve.

Norway spruce (Aidun and Egertsdotter, 2012; Mamun et al., 2018) using the model with separate container for medium that reduces humidity in the culture area (Figure 3). The immersion time was adjusted to allow the liquid medium to immerse the cultures, then to immediately retract without soaking. This typically results in immersions of $15-30 \mathrm{~s}$ duration. For multiplication and maturation, standard settings for immersions are 2-4 times every $24 \mathrm{~h}$, depending on cell line.

Efforts toward automation and scale up of the bioreactor process for multiplication of conifer SE cultures have been attempted with bioreactors based on the same principal as the single-use wave-mixed bag-system in use for mammalian cell culture (Swanda, 2015a; single-use bioreactors reviewed in Eibl et al. (2010); use for plant cell culture in general reviewed in Eibl et al. (2018). In brief, such bioreactors are based on full immersion of the culture in liquid, enclosed in a plastic bag. The bag is placed on a moving platform to create movement of the liquid for aeration. Similarly to the mammalian use bioreactors, the bioreactor system intended primarily for conifers has different ports, which could be used for attaching different types of sensors (e.g., for temperature, salts, $\mathrm{pH}$ ), or transporting culture material in or out of the bioreactor with the action of a pump. The system can also be equipped with an automated gas control (Swanda, 2015b). To date there are however no publications showing successful use of such bioreactor system for SE cultures in conifers. On the contrary, for commercial scale up of SE plant production in Coffea canephora, cultures are multiplied in a $10 \mathrm{~L}$ disposable bioreactor consisting of a bag containing a rigid plastic box. Further developments are plastic-based disposable bioreactors for 10 to $100 \mathrm{~L}$ working volumes of coffee, enabled by successful introduction of a bag system for production of torpedo-stage embryos (Ducos et al., 2009) In this system, full liquid-immersion plastic bag bioreactors are utilized for SE-multiplication to torpedo stage embryos, followed by production of cotyledonary embryos in temporary immersion bioreactors. Cotyledonary stage embryos are then transferred to ex vitro conditions and manually planted. For Coffea arabica, Etienne et al. (2013) designed a polycarbonate bioreactor (MATIS) similar to a RITA but of 5L volume, with a larger area allowing the spreading out of the biomass to obtain 
greater light transmittance. This raised the embryo-to-plantlet conversion from 55 to $91 \%$. A major difference between the conifer and angiosperm SE process so far preventing the same processes to be successful for conifer SE plant production may be the typically required step of desiccation after production of mature (cotyledonary stage) conifer somatic embryos, and the apparent benefit on germination from cleaning off PEMs and medium components like PEG from the mature embryos before germination.

Efforts with other angiosperm species have been mostly in temporary immersion bioreactors, e.g., RITA bioreactor types, but some other types have also been tested (examples in Table 1). Additional species and details on different bioreactor designs have been described earlier in a book focused on bioreactor utilization (Hvoslef-Eide and Preil, 2005). In a broadly aimed effort to scale up liquid SE suspension cultures, a custom-made bioreactor holding $2 \mathrm{~L}$ liquid medium and equipped with stirrers and oxygenation was tested. Increased rates of multiplication rates were observed for embryogenic cultures of carrot (Daucus carota), Norway spruce (Picea abies), birch (Betula pendula), cyclamen (Cyclamen persicum), and shoot cultures of Christmas begonia (Begonia $x$ cheimantha) in custom-made bioreactors (Hvoslef-Eide et al., 2005).

Although there are many reports of positive response to culture in temporary immersion bioreactors, other types of bioreactors have sometimes been shown to pose some stress to the somatic embryo development. In barley the embryogenic potential of cultures was significantly reduced in $2 \mathrm{~L}$ suspension culture bioreactors with agitation speed of $60 \mathrm{rpm}$ as compared with the conventional small vessels (Stirn et al., 1994). It was observed that Ipomoea batatas embryos were ruptured and damaged when cultured in airlift bioreactors, resulting in limited production of embryos in these bioreactors. The shear stress of flushing fresh air inside airlift bioreactor was believed to cause the embryogenic damage during somatic embryo production and development (Bienick et al., 1995).

Overall, as concluded in an earlier review (Ascough et al., 2004), liquid SE cultures in bioreactors can show better growth and proliferation of different stages of the SE culture process, and better root and shoot formation, than those on solidified media. The reason may be better availability of nutrients and water, but some problems associated with liquid cultures such as hyperhydricity and injury to somatic embryos should be addressed by improved culture conditions.

\section{Singularization and Harvest of Mature Somatic Embryos}

When many early stage somatic embryos of the multiplying culture will not respond to the maturation treatment but remain as PEMs, it is necessary to harvest the mature embryos by separation from the PEMs. Too many decaying PEMs will affect the down-stream developmental processes of the mature embryo during germination. The harvest of individual mature embryos from the maturation-culture is arguably the most timeconsuming step in the process of producing SE plants (in conifers). Automation of such a process of isolating mature embryos from the residual tissue of PEMs has also been attempted in various approaches for the purpose of scale up.
One process is described that utilizes a liquid medium for spreading out isolated embryos across a porous substrate. The substrate is designed to be manipulated to accommodate the mature somatic embryos through desiccation and germination by the aid of a robotic arm moving pieces of porous material holding mature embryos (Swanda and Givens, 2017). Another more recent system, the SE Fluidics System (Aidun, 2018; Aidun and Egertsdotter, 2018) handles the SE cultures of PEMs and mature embryos in liquid through dispersion of the mature embryos and PEM tissue (Aidun, 2015; Aidun and Egertsdotter, 2015), separation of mature embryos, and an image analysis that compares individual harvested embryos to the pre-set selection criteria (Figure 4). A pilot-scale factory at SweTree Technologies in Uppsala, Sweden, based around an SE Fluidics System was run between 2014 and 2016 to demonstrate a pilot production capacity of 1 million plants/year. Current joint efforts of Swedish forestry companies and SweTree Technologies aim toward larger-scale production facilities based on a similar system with an annual commercial production of 10 million SE plants.

Robotics-based technology development was initiated for isolation, selection, and handling of mature somatic embryos for quality assessment, sorting and orientation of mature embryos of Abies nordmanniana and Picea sitchensis (Find and Krogstrup, 2008). No further development of this technology has however been reported. Robotics combined with image analyses has also been utilized for selection and handling mature embryos and germinants as part of the concept for developing an artificial seed. A system for automatically harvesting and screening mature embryos for the purpose of selecting the best embryos for insertion into artificial seeds was developed (Timmis et al., 2010). The system uses vibrational sieving, moving embryos by liquid jets and handling of embryos by robotics to sort and separate embryos according to size and shape, supported by image analysis to identify embryos most likely to germinate.

In another effort to reduce labor and build a foundation for automation and scale up by automating the step of embryoharvest, a set up was designed for washing cultures of mature embryos free from PEMs and PEG and transfer of isolated embryos to a substrate for germination preparation (Nehra et al., 2012). Further efforts to automate the process of harvesting mature embryos and process individual harvested embryos during desiccation for germination has been described in a series of patents (most recently in Swanda and Givens, 2017).

\section{Germination and Artificial Seeds}

An idea that attracted much attention and praise from the traditional forestry industry is based on the concept of embedding the somatic embryos into an artificial seed. The goal is to allow storage and handling of the somatic embryo in the same way as the regular seed, which is anticipated to reduce the cost of adapting the handling technologies to somatic embryos. Artificial seed technology was extensively researched and different aspects supporting the concept developed (Sharma et al., 2013; Guan et al., 2016). Automated preparation of manufactured, artificial seeds followed by insertion of selected embryos is described in Hirahara (2009). A major unresolved problem with artificial seeds of woody species has been low and 
TABLE 1 | Representative published articles on the utilization of bioreactors for SE-based plant production in angiosperms.

\begin{tabular}{|c|c|c|c|}
\hline Species & Type of bioreactor & Comments on key content & References \\
\hline $\begin{array}{l}\text { Allium cepa } \\
\text { (onion) }\end{array}$ & $\begin{array}{l}3 \mathrm{~L} \text { balloon type air lift, with } \\
\text { continuous or temporary immersion }\end{array}$ & $\begin{array}{l}\text { Nearly twice as fast proliferation with continuous as compared } \\
\text { with temporary immersion }\end{array}$ & Wu et al., 2015 \\
\hline \multirow[t]{2}{*}{$\begin{array}{l}\text { Bactris gasipaes } \\
\text { (peach palm) }\end{array}$} & RITA and twin flask system & $\begin{array}{l}\text { Higher quality PEMs giving four times as many plants obtained } \\
\text { from RITA than from twin flasks }\end{array}$ & Heringer et al., 2014 \\
\hline & $\begin{array}{l}\text { Temporary immersion system (twin } \\
\text { flasks) }\end{array}$ & $\begin{array}{l}\text { Induction of secondary SE was higher (84.6\%) in bioreactor than } \\
\text { on solid medium }(70.2 \%)\end{array}$ & $\begin{array}{l}\text { Steinmacher et al., } \\
2011\end{array}$ \\
\hline $\begin{array}{l}\text { Camellia sinensis } \\
\text { (tea) }\end{array}$ & $\begin{array}{l}\text { Custom temporary immersion } \\
\text { bioreactor }\end{array}$ & $\begin{array}{l}\text { Four-fold higher yield of gobular embryos with TIS than obtained } \\
\text { on semi-solid media }\end{array}$ & Akula et al., 2000 \\
\hline Carica papaya (papaya) & RITA & $\begin{array}{l}\text { Up to } 95 \% \text { of SEs showed complete germination in RITA } \\
\text { depending on inoculum density }\end{array}$ & $\begin{array}{l}\text { Posada-Pérez et al., } \\
2017\end{array}$ \\
\hline Castanea dentata (American & Airlift bioreactors (ALBs) & Higher yields of small cell clumps suitable for transformation in & Kong et al., 2014 \\
\hline
\end{tabular}

Chestnut), (C. dentata $x$

ALBs than in suspension flasks

Castanea

mollissima)

(American-Chinese chestnut

back crosses)

Citrus deliciosa

Custom-made temporary immersion bioreactor

Coffea arabica L.

(arabica coffee)

RITA and MATIS
Coffea canephora (robusta coffee)

Elaeis guineensis (oil palm)

Eleutherococcus senticosus Maxim

(Siberian ginseng)

Eurycoma longifolia

Hevea brasiliensis (rubber)

Kalopanax septemlobus

Leucojum aestivum
RITA

RITA

RITA

RITA

Temporary immersion bioreactors (TIBS)

$10 \mathrm{~L}$ "Box- in- bag" bioreactors, TIBs

Custom-made temporary immersion system modified from Nalgene filter units

RITA

RITA and twin flask system TIS

Bubble column bioreactor

RITA

Custom-made temporary immersion bioreactor

Temporary immersion $2 \mathrm{~L}$ bioreactors with net, (TIN) or continuous immersion with net $(\mathrm{CIN})$

RITA
TIB stimulated formation of cotyledonary stage embryos, but germination still poor in all culture conditons

Comparison of zygotic and somatic embryo germination and plant formation provides information to improve SE germination in larger bioreactors.

Effects on yields and vitrification from immersion cycles. Six immersions/day produced more embryos $(3,081)$ than two immersions/day $(2,094)$

Demonstration of benefits from germination in RITAs for direct sowing in soil. $200 \mathrm{mg}$ of embryogenic callus produced 8,000 embryos in one bioreactor. The germination frequency was $66 \%$ 800 somatic embryo per bioreactors were produced. Germination rate was $86 \%$. A positive relation of cotyledon size of embryos germinated in RITA for plant establishment

Highest number of somatic embryos (25) obtained in bioreactor. The germination rate was $100 \%$. SE-multiplication in suspension cultures and plant regeneration in RITA for the purpose of genetic transformation

Pilot scale process for batch-production of torpedo stage embryos in suspension flasks, germination in TIBs and transfer to ex vitro after storage

Batch-production of torpedo stage embryos in "Box-in-bag bioreactor," germination in TIBs and transfer to ex vitro after storage

Growth rate of embryogenic callus was $0.38 \mathrm{~g} /$ week

Fresh weight of callus increased 7-fold in RITA bioreactors $100 \%$ increase in fresh biomass in twin flask compared with RITA Higher numbers of somatic embryos and better growth developed in bioreactors than in suspension cultures

Optimization of immersion intervals and demonstration of plant regeneration after RITA embryo production

Improved yields in all steps of the SE process from embryogeneic callus to germination

$85 \%$ of embryos produced plantlets with TIN, vs. $29 \%$ with CIN

$46 \%$ increased efffects from culture system on secondary metabolite production in somatic embryo cultures
Cabasson et al., 1997

Etienne et al., 2013

Albarrán et al., 2005

Etienne-Barry et al., 1999

Barry-Etienne et al., 2002

Gatica-Arias et al., 2008

Ducos et al., 2007

Ducos et al., 2009

Sumaryono et al., 2008

Marbun et al., 2015

Gomes et al., 2016

Yang et al., 2012

Mohd et al., 2017

Etienne et al., 1997

Kim et al., 2011

Ptak et al., 2013 
TABLE 1 | Continued

\begin{tabular}{|c|c|c|c|}
\hline Species & Type of bioreactor & Comments on key content & References \\
\hline $\begin{array}{l}\text { Musa acuminata } \\
\text { (banana) }\end{array}$ & $\begin{array}{l}5 \mathrm{~L} \text { balloon type bubble column } \\
\text { bioreactor or shake flasks }\end{array}$ & $\begin{array}{l}\text { Highest frequency ( } 87 \%) \text { normal plants obtained among } \\
\text { regenerants after callus proliferation in a } \mathrm{pH} \text {-controlled bioreactor }\end{array}$ & Chin et al., 2014 \\
\hline $\begin{array}{l}\text { Musa ssp. (banana and } \\
\text { plantain) }\end{array}$ & $\begin{array}{l}\text { Temporary immersion system } \\
\text { modified from Nalgene filter units, or } \\
\text { semi-solid medium }\end{array}$ & $\begin{array}{l}\text { Number of embryos muliplied } 9 \text {-fold after } 2 \text { months in bioreactor, } \\
3 \text {-fold on semi-solid medium. Subsequent germination on } \\
\text { semisolid medium was } 60-70 \% \text { in both cases }\end{array}$ & Escalant et al., 1994 \\
\hline Panax notoginseng & $3 \mathrm{~L}$ air lift bioreactor & $\begin{array}{l}\text { Early globular embryos }(10 \mathrm{~g}) \text { developed into cotyledonary } \\
\text { embryos }(79.7 \mathrm{~g}) \text { in } 4 \text { weeks in bioreactor. These converted to } \\
\text { plantlets if treated with GA. }\end{array}$ & You et al., 2012 \\
\hline \multirow[t]{3}{*}{$\begin{array}{l}\text { Phoenix dactylifera L. (date } \\
\text { palm) }\end{array}$} & TIS & $\begin{array}{l}\text { A mixed system including culture on semi-solid medium, reduced } \\
\text { costs (vs. traditional methods) and the time for plantlet production } \\
\text { reduced to }<3 \text { years }\end{array}$ & Almusawi et al., 2017 \\
\hline & $\begin{array}{l}\text { Custom temporary immersion system } \\
\text { bioreactor }\end{array}$ & $\begin{array}{l}\text { Formation of } 172 \text { somatic embryos per bioreactor from } 500 \text { mg } \\
\text { embryogenic callus }\end{array}$ & Al mayahi, 2015 \\
\hline & RITA & Suspension cultures gave more embryos than RITA & Ibraheem et al., 2013 \\
\hline $\begin{array}{l}\text { Quercus robur } \\
\text { (common oak) }\end{array}$ & RITA & $\begin{array}{l}\text { Improved proliferation and production of cotyledonary stage } \\
\text { embryos in temporary immersion bioreactors compared to } \\
\text { semi-solid medium; } 20 \% \text { increase }\end{array}$ & Mallón et al., 2012 \\
\hline Quercus suber (cork oak) & RITA & $\begin{array}{l}7.5 \text { fold increase in fresh weight in RITA compared with on } \\
\text { semisolid medium. Immersion frequency had strong influence; } \\
\text { best I min every } 4 \text { or } 6 \mathrm{~h}\end{array}$ & Perez et al., 2013 \\
\hline $\begin{array}{l}\text { Saccharum officinarum } \\
\text { (sugar cane) }\end{array}$ & RITA & $\begin{array}{l}\text { Increased yield of in vitro produced plants in RITA compared to } \\
\text { semi-solid culture }\end{array}$ & Snyman et al., 2011 \\
\hline $\begin{array}{l}\text { Theobroma cacao } \\
\text { (cocoa) }\end{array}$ & Twin flask TIS bioreactors & $\begin{array}{l}\text { Significantly higher numbers of embryos in TIS than on solid } \\
\text { medium. Improved conversion rate to torpedo-shape }\end{array}$ & Niemenak et al., 2008 \\
\hline Vitis amurensis & $3 \mathrm{~L}$ balloon-type air lift bioreactor & $\begin{array}{l}\text { SE biomass growth was higher in bioreactor }(328.45 \mathrm{~g} / \mathrm{L}) \text { than on } \\
\text { solid medium }(69.60 \mathrm{~g} / \mathrm{L})\end{array}$ & Sun et al., 2016 \\
\hline Vitis vinifera $L$. & Air-lift bioreactor & $\begin{array}{l}\text { Pro-embryogenic masses doubled in fresh weight in bioreactors } \\
\text { compared to suspension flasks without any losses in viability and } \\
\text { regenerative capacity }\end{array}$ & Tapia et al., 2009 \\
\hline
\end{tabular}

variable conversion rates to viable plants (Guan et al., 2016). Related to this are contamination problems caused by sucrose in the germination media.

An attractive alternative method to the artificial seed concept is however direct sowing of mature somatic embryos into a nonsterile environment. Such a method is claimed to be successful by placing embryos into an environment with specific humidity, temperature, nutrients, ambient light intensity and diurnal photoperiod, and shown to enable and facilitate germination (Polonenko et al., 2005). To date this has not been made to work on a practical scale.

\section{Germination and Planting}

The steps following harvest of mature somatic embryos of conifers typically but not necessarily involve partial drying or desiccation of the mature embryos, followed by germination of the mature somatic embryo. Once the embryo is deemed to have sufficiently germinated by developing a root and a shoot, the germinant should be planted into a suitable compost. This process is considered another key rate-limiting step as the germinated embryos are fragile and often display different morphologies. Efforts to automate the process include an initial step of transferring the harvested mature embryos from the surface on which they were collected to germination medium by an automated process, and providing the necessary conditions for germination after transfer to the second surface (Jamruszka-Lewis and Starr, 2017).

In another recent effort to automate germination and planting, a system was developed that combines these steps through a connected process taking mature embryos harvested with the SE fluidics system through a germination platform allowing the mature embryos to be desiccated, germinated by contact with liquid medium, and then planted directly from the same position it was deposited after harvesting by the SE Fluidics system, as described in detail in Aidun and Egertsdotter (2018). The direct planting is performed by an automated planting system that is specifically designed to handle the germinated embryo from the germination platform after harvest with the SE Fluidics system (Aidun, 2016).

For carrot plant production from somatic embryos, a simplistic system utilizing a mist bioreactor was shown to work well simply by controlling the nutrient supply and aeration at each stage after a single set up of the apparatus, thus largely automating the whole SE process (Fei and Weathers, 2014).

Automated planting of seed into pots, and transplanting of plants from small pots to larger pots, are technologies that have been in use for a long time. Such automation can be applied to SE plants once the SE plant is established and growing ex vitro. However, for the steps before the SE plant is growing 

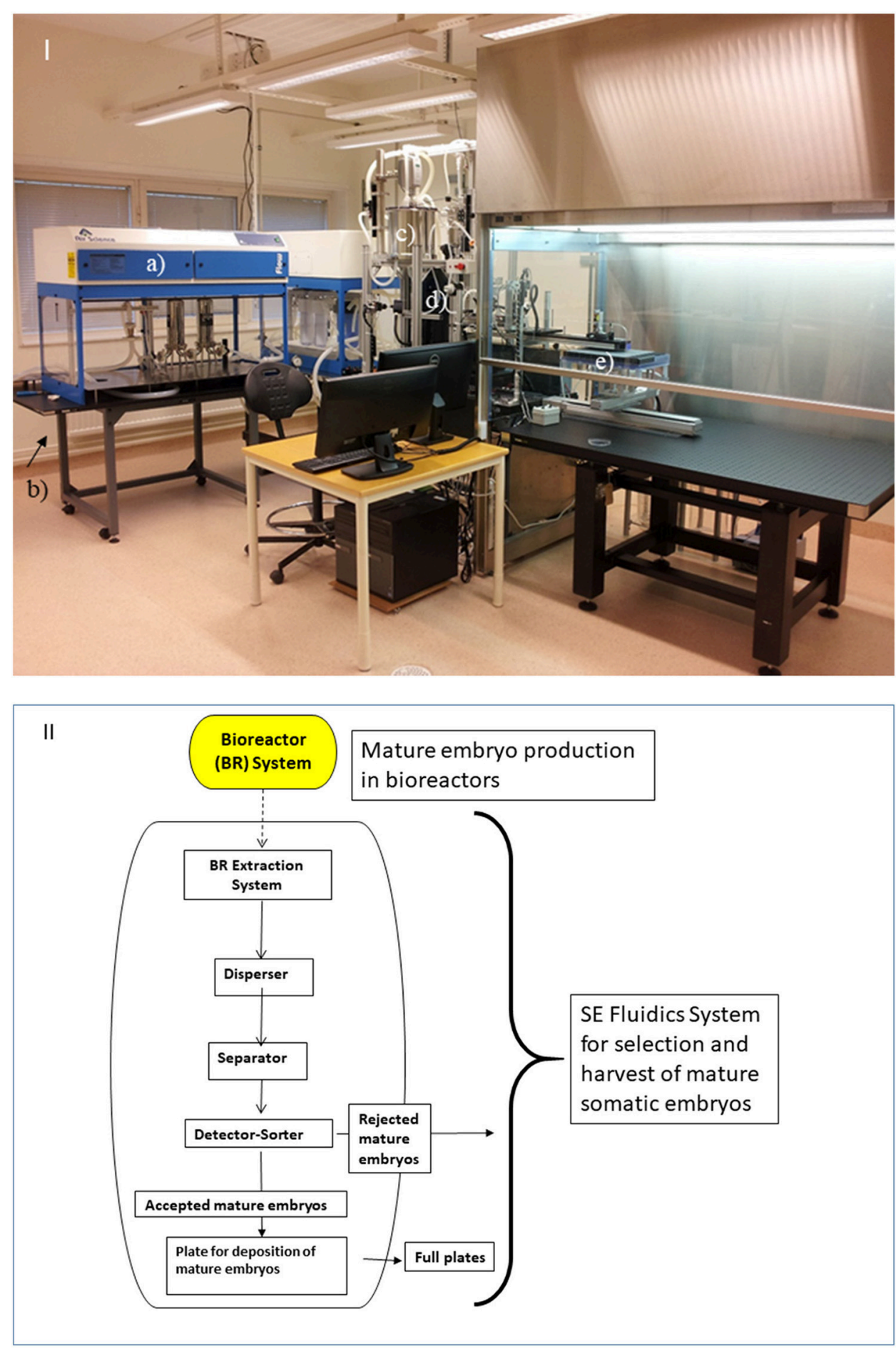

FIGURE 4 | An SE Fluidics System in use for research at Umeå Plant Science Center, Swedish University of Agricultural Sciences in Umeå, Sweden. I. Overview of the SE Fluidics System and the main functional parts: The core parts of the system are: (a) a laminar flow hood for extraction of tissue from the bioreactors (or other culture vessels); (b) disperser-system that disperses the culture of PEMs and embryos; (c) a separator tank that separates out mature embryos for (d) image analysis. (e) Mature embryos are deposited into the container or substrate of choice. II. Flow chart showing the various steps in the SE fluidics system from proliferation and maturation in bioreactor to transfer (extraction) of the mature embryos and unresponsive PEM masses from the bioreactors into the SE Fluidics system; dispersion of the tissue from the bioreactors into mature embryos and clusters of PEMs; separation of mature embryos from the PEMs, with only mature embryos proceeding in the SE Fluidics system after the separator tank; optional image analysis of mature embryos and sorting based on pre-set selection criteria, and deposition of selected mature embryos. The system can also be run without image analysis where all mature embryos are harvested, or with image analysis where all embryos are imaged but without selection based on specific morphologies. For details of the constructions, see Aidun and Egertsdotter (2018). 
ex vitro, including the planting of the germinated mature embryo into compost, there is no known, well established automated technology currently in use for commercial SE plant production, although the Germination Platform technology developed as an add-on technology for the SE Fluidics system has the potential to handle this step.

Production of cuttings from SE-plants has been adopted on a larger scale for conifer species that are amenable to taking cuttings, notably Picea sitchensis (Thompson, 2013), Pinus radiata (Montalbán et al., 2011) and Pinus taeda (Schapovaloff and Raute, 2016). As there are no widely adopted automation procedures for production of cuttings, the use of two propagation techniques will further raise the costs due to additional manual labor.

In Sweden, millions of tree seedlings are produced every year of which $98 \%$ are of conifer species. Different companies deliver millions of seedlings from their nurseries to other forest companies and forest owners and this demand has been increasing over the last 15 years. Such huge numbers of seedlings make it imperative to automate the whole process. In Swedish forest nurseries the automated systems are in use for sorting seedlings with cameras, stacking, packaging, making pellet, transplanting, efficient seedling shipping and distribution. Different companies have adopted different methods of storing, packaging, and transplanting seedlings. Some companies have advantages over others in terms of efficient mechanizations, easy handling, cost effectiveness, and shorter delivery time (Ersson, 2016). The existence of such automated systems in the nursery sites will be helpful for implementation of SE plant production that is based on containerized plant production.

\section{STATE OF THE ART AND FUTURE PERSPECTIVES}

As of today, no automated systems for large-scale production of somatic embryo plants are yet in commercial use. The SE Fluidics system supports singularization, selection and deposition of

\section{REFERENCES}

Aidun, C. K. (2015). Methods for Dispersing Somatic Plant Embryos. U.S. Patent No US 8,927,287 B2. Washington, DC: U.S. Patent and Trademark Office.

Aidun, C. K. (2016). Planting Method and Device for Plant Propagules. U.S. Patent Application No US 2016/0316639 A1. Washington, DC: U.S. Patent and Trademark Office.

Aidun, C. K. (2018). Separator Device, Depostion Device, and System for Handling of Somatic Embryos. U.S. Patent No: US 10,004,189 B2. Washington, DC: U.S. Patent and Trademark Office.

Aidun, C. K., and Egertsdotter, E.-M. U. (2015). Method for Dispersion of Assemblies of Biological Material. U.S. Patent No US8927287B2. Washington, DC: U.S. Patent and Trademark Office.

Aidun, C. K., and Egertsdotter, U. (2012). "Fluidics-based automation of clonal propagation via somatic embryogenesis: SE-fluidics system," in Proc. 2nd IUFRO Working Party 2.09.02 25-8 June 2012 (Bruno).

Aidun, C. K., and Egertsdotter, U. (2018). "SE fluidics system," in Step Wise Protocols for Somatic Embryogenesis of Important Woody Plants, Volume I, eds. S. M. Jain and P. Gupta (Cham: Springer International Publishing), 211-227. mature somatic embryos and can enable large-scale production of SE plants of conifers by overcoming the labor-intensive steps of harvesting and separating good mature embryos from the culture mix of mature embryos and non-responsive PEMs. Such a system is planned to become the core of a full commercial system for SE plant production of Norway spruce in Sweden. Further development of the GP system and vertical germination as described in Aidun and Egertsdotter (2018) holds promise for generating better-quality germinants coupled with the option to automated planting into the non-sterile substrate. It however appears that the immediate future for applying SE for large-scale plant production is based on selection of cell lines permissive to the SE process, from a very large number of improved seeds. Numerous attempts to optimize the medium and growth conditions have not made significant differences, but finding the "best" cell lines for the existing methods in the labs greatly enhances the results. Furthermore, improving the selection criteria for "good" mature embryos will improve the downstream yields of plants. Efforts have been made to design a classificationsystem for plant embryos that uses a logistic regression model based on image or spectral data correlated with various quality aspects (Timmis and Toland, 2009). The possibilities to utilize spectral imaging have recently been demonstrated for analyses of chemical composition of intact maize kernels (Yang et al., 2018). Furthermore, the future perspective of utilizing hyperspectral imaging has the possibility to further distinguish detailed characteristics of mature embryos likely to germinate and form plants ( $\mathrm{Lu}$ and Fei, 2014). In Theobroma cacao, transformants with genes controlling transcription factors show greatly enhanced SE performance (Shires et al., 2017) and references therein.

\section{AUTHOR CONTRIBUTIONS}

UE edited and wrote the bulk of the manuscript, and directed co-authors. IA and DC contributed to parts of the manuscript writing. DC edited and checked the language.
Akula, A., Becker, D., and Bateson, M. (2000). High-yielding repetitive somatic embryogenesis and plant recovery in a selected tea clone, 'TRI-2025', by temporary immersion. Plant Cell Rep. 19, 1140-1145. doi: $10.1007 / \mathrm{s} 002990000239$

Al mayahi, A. W. M. (2015). An efficient protocol for indirect somatic embryogenesis and shoot organogenesis from leaf segments of date palm (Phoenix dactylifera L.) CV. Quntar. Afr. J. Agric. Res. 10:1031-1042. doi: 10.5897/AJAR2014.9305

Albarrán, J., Bertrand, B., Lartaud, M., and Etienne, H. (2005). Cycle characteristics in a temporary immersion bioreactor affect regeneration, morphology, water and mineral status of coffee (Coffea arabica) somatic embryos. Plant Cell Tiss. Organ Cult. 81, 27-36. doi: 10.1007/s11240-004-2618-8

Almusawi, A. H. A., Sayegh, A. J., Alshanaw, A. M. S., and Griffis, J. L. (2017). "Plantform bioreactor for mass micropropagation of date palm," in Date Palm Biotechnology Protocols Volume I: Tissue Culture Applications, eds J. M. AlKhayri, S. M. Jain and D. V. Johnson (New York, NY: Springer New York), 251-265.

Ascough, G. D., Fennell, C. W., and Van Staden, J. (2004). The regulation of plant growth and development in liquid culture. South Afric. J. Bot. 70, 181-190. doi: 10.1016/S.0254-6299(15)30234-9 
Attree, S. M., and Fowke, L.C. (1993). Embryogeny of gymnosperms: advances in synthetic seed technology of conifers. PLant Cell Tiss. Organ Cult. 35, 1-35. doi: 10.1007/BF00043936

Barry-Etienne, D., Bertrand, B., Schlönvoigt, A., and Etienne, H. (2002). The morphological variability within a population of coffee somatic embryos produced in a bioreactor affects the regeneration and the development of plants in the nursery. Plant Cell Tiss. Organ Cult. 68, 153-162. doi: 10.1023/A:1013874221569

Beaulieu, J., Doerksen, T., Clément, S., MacKey, J., and Bousquet, J. (2014). Accuracy of genomic selection models in a large population of open-pollinated families in white spruce. Heredity 113, 343-352. doi: 10.1038/hdy.2014.36

Bienick, M. E., Harrell, R. C., and Cantliffe, D. J. (1995). Enhancement of somatic embryogenesis of Ipomoea batatas in solid eultures and production of mature somatic embryos in liquid cultures for application to a bioreactor production system. Plant Cell Tiss. Organ Cult. 41, 1-8. doi: 10.1007/BF00124080

Businge, E., Trifonova, A., Schneider, C., Rodel, P., and Egertsdotter, U. (2017). Evaluation of a new temporary immersion bioreactor system for micropropagation of cultivars of Eucalyptus, birch and fir. Forests 8:196. doi: $10.3390 / 88060196$

Cabasson, C., Alvard, D., Dambier, D., Ollitrault, P.,and, C., Teisson (1997). Improvement of Citrus somatic embryo development by temporary immersion. Plant Cell Tiss. Organ Cult. 50, 33-37. doi: 10.1023/A:1005896725780

Cairney, J., and Pullman, G. S. (2007). The cellular and molecular biology of conifer embryogenesis. New Phytol. 176, 511-536. doi: 10.1111/j.1469-8137.2007.02239.x

Carlsson, J., Svennerstam, H., Moritz, T., Egertsdotter, U., and Ganeteg, U. (2017). Nitrogen uptake and assimilation in proliferating embryogenic cultures of Norway spruce-investigating the specific role of glutamine. PLOS ONE 12:e0181785. doi: 10.1371/journal.pone.0181785

Cervelli, R., and Senaratna, T. (1995). "Economic aspects of somatic embryogenesis," in Automation and Environmental Control in Plant Tissue Culture, eds J. Aitken-Christie, T. Kozai and M. A. L. Smith (Dordrecht: Springer Netherlands), 29-64.

Chin, W. Y. W., Annuar, M. S. M., Tan, B. C., and Khalid, N. (2014). Evaluation of a laboratory scale conventional shake flask and a bioreactor on cell growth and regeneration of banana cell suspension cultures. Sci. Hort. 172, 39-46. doi: 10.1016/j.scienta.2014.03.042

Dobrowolska, I., Andrade, G. M., Clapham, D., and Egertsdotter, U. (2017). Histological analysis reveals the formation of shoots rather than embryos in regenerating cultures of Eucalyptus globulus. Plant Cell Tiss. Org. Cult. 128, 319-326. doi: 10.1007/s11240-016-1111-5

Ducos, J. P., Labbe, G., Lambot, C., and Pétiard, V. (2007). Pilot scale process for the production of pre-germinated somatic embryos of selected robusta (Coffea canephora) clones. In vitro Cell. Dev. Biol. Plant 43, 652-659. doi: 10.1007/s11627-007-9075-0

Ducos, J. P., Terrier, B., and Courtois, D. (2009). Disposable bioreactors for plant micropropagation and mass plant cell culture. Adv. Biochem. Engin. Biotechnol. 115, 89-115. doi: 10.1007/10_2008_28

Egertsdotter, E. U. (1996). Regulation of Somatic Embryo Development in Norway Spruce (Picea abies). Research Notes 52, Dissertation, SLU, Uppsala, Sweden ISSN 0348-565X.

Egertsdotter, U. (2018). Plant physiological and genetical aspects of the somatic embryogenesis process in conifers. Scand. J. For.Res. doi: 10.1080/02827581.2018.1441433. [Epub ahead of print].

Egertsdotter, U., and Clapham, D. (2011). Method for Maturing and Synchronizing Conifer somatic Embryos. U.S. Patent No US 9,125,352 B2. Washington, DC: U.S. Patent and Trademark Office.

Egertsdotter, U., and von Arnold, S. (1998). Development of somatic embryos in Norway spruce. J. Exp. Bot. 49, 155-162. doi: 10.1093/jxb/49.319.155

Eibl, R., Kaiser, S., Lombriser, R., and Eibl, D. (2010). Disposable bioreactors: the current state-of-the-art and recommended applications in biotechnology. Appl. Microbiol. Biotechnol. 86, 41-49. doi: 10.1007/s00253-009-2422-9

Eibl, R., Meier, P., Stutz, I., Schildberger, D., Hühn, T., and Eibl, D. (2018). Plant cell culture technology in the cosmetics and food industries: current state and future trends. Appl. Micobiol. Biotechnol. 102, 8661-8675. doi: $10.1007 / \mathrm{s} 00253-018-9279-8$

Ekberg, I., Eriksson, G., and Dormling, I. (1979). Photoperiodic reactions in conifer species. Holarctic Ecol. 2, 255-263. doi: 10.1111/j.1600-0587.1979.tb01297.x
Ersson, T. (2016). Review of transplanting and seedling packaging systems in Swedish tree nurseries. FOP Technical Report No 38.

Escalant, J.-V., Teisson, C., and Cote, F. (1994). Amplified somatic embryogenesis from male flowers of triploid banana and plantain cultivars (Musa spp.). In vitro Cell Dev. Biol. Plant 30, 181-186. doi: 10.1007/BF02823029

Etienne, H., Bertrand, B., Georget, F., Lartaud, M., Montes, F., Dechamp, E., et al. (2013). Development of coffee somatic and zygotic embryos to plants differs in the morphological, histochemical and hydration aspects. Tree Physiol. 33, 640-653 doi: 10.1093/treephys/tpt034

Etienne, H., Lartaud, M., Michaux-Ferriere, N., Carron, M.-P., Berthouly, M., and Teisson, C. (1997). Improvement of somatic embryogenesis in Hevea brasiliensis (Müll. Arg.) using the temporary immersion technique. In vitro Cell Dev. Biol. Plant 33: 81-87. doi: 10.1007/s11627-997-0001-2

Etienne-Barry, D., Bertrand, B., Vasquez, N., and Etienne, H. (1999). Direct sowing of Coffea arabica somatic embryos mass-produced in a bioreactor and regeneration of plants. Plant Cell Rep. 19, 111-117 doi: 10.1007/s002990050720

Fehér, A., Pasternak, T. P., and Dudits, D. (2003). Transition of somatic plant cells to an embryogenic state. Plant Cell Tiss. Organ Cult. 74, 201-228. doi: 10.1023/A:1024033216561

Fei, L., and Weathers, P. J. (2014). From cells to embryos to rooted plantlets in a mist bioreactor. Plant Cell Tiss. Organ Cult. 116, 37-46. doi: 10.1007/s11240-013-0380-5

Filonova, L. H., Bozhkov, P. V., Brukhin, V. B., Daniel, G., Zhivotovsky, B., and von Arnold, S. (2000a). Two waves of programmed cell death occur during formation and development of somatic embryos in the gymnosperm, Norway spruce. J. Cell Sci. 113, 4399-4411.

Filonova, L. H., Bozhkov, P. V., and von Arnold, S. (2000b). Developmental pathway of somatic embryogenesis in Picea abies as revealed by time-lapse tracking. J. Exp. Bot. 51, 249-264. doi: 10.1093/jexbot/51.343.249

Find, J., and Krogstrup, P. (2008). "Integration of biotechnology, robot technoplogy and visualisation technology for development of methods for autamated mass production of elite trees: automated plant production by somatic embryogenesis," in Vegetative Propagation of Conifers for Enhancing Landscaping and Tree Breeding, Working Papers of the Finnish Forest Reseach Institute (Finnish Forest Research Institute, Finland) Proceedings of the Nordic Meeting held in September 10th-11th 2008, eds T. Aronen, T. Nikkanen, and T. Tynkkynen, (Punkaharju), 114, 72-77.

Fujimura, T., and Komamine, A. (1979). Synchronization of somatic embryogenesis in a carrot cell suspension culture. Plant Physiol. 64, 162-164. doi: $10.1104 / p p .64 .1 .162$

Gatica-Arias, A. M., Arrieta-Espinoza, G., and Esquivel, A. M. E. (2008). Plant regeneration via indirect somatic embryogenesis and optimisation of genetic transformation in Coffea arabica L. cvs. Caturra and Catuaí. Elect. J. Biotechnol. 11, 1-12. doi: 10.2225/vol11-issue1-fulltext-9

Gomes, H. T., Bartos, P. M. C., Balzon, T. A., and Scherwinski-Pereira, J. E. (2016). Regeneration of somatic embryos of oil palm (Elaeis guineensis) using temporary immersion bioreactors. Industr. Crops Products 89, 244-249. doi: 10.1016/j.indcrop.2016.05.021

Gorbatenko, O., and Hakman, I. (2001). Desiccation tolerant somatic embryos of Norway spruce (Picea abies) can be produced in liquid cultures and regenerated into plantlets. Internat. J. Plant Sci. 162, 1211-1218. doi: 10.1086/323416

Guan, Y., Li, S.-G., Fan, X.-F., and Su, Z.-H. (2016). Application of somatic embryogenesis in woody plants. Front. Plant Sci. 7:938. doi: $10.3389 /$ fpls.2016.00938

Hakman, I., and von Arnold, S. (1988). Somatic embryogenesis and plant regeneration from suspension cultures of Picea glauca (White spruce). Physiol. Plant. 72, 579-587. doi: 10.1111/j.1399-3054.1988.tb09168.x

Halperin, W. (1995). "In vitro embryogenesis: some historical issues and unresolved problems," in In vitro Embryogenesis in Plants, eds T. A. Thorpe (Dordrecht: Springer Netherlands), 1-16.

Heringer, A. S., Steinmacher, D. A., Fraga, H. P. F., Vieira, L. N., Montagna, T., Quinga, L., et al. (2014). Improved high-efficiency protocol for somatic embryogenesis in Peach Palm (Bactris gasipaes Kunth) using RITA temporary immersion system. Sci. Hort. 179, 284-292. doi: 10.1016/j.scienta.2014.09.041

Heyerdahl, P. H., Olsen, O. A. S., and Hvoslef-Eide, A. K. (1995). "Engineering aspects of plant propagation in bioreactors," in Automation and Environmental Control in Plant Tissue Culture, eds J. Aitken-Christie, T. Kozai and M.A.L. Smith (Dordrecht: Springer Netherlands), 87-123. 
Hirahara, E. (2009). Method and system for Producing Manufactured Seeds. US 7,568,309 B2. Washington, DC: U.S. Patent and Trademark Office.

Högberg, K.-A., Bozhkov, P. V., Grönroos, R., and von Arnold, S. (2001). Critical factors affecting ex vitro performance of somatic embryo plants of Picea abies. Scand. J. For. Res. 16, 295-304. doi: 10.1080/02827580116772

Hvoslef-Eide, A. K., Olsen, O.,a,.S., Lyngved, R., Munster, C., and Heyerdahl, P.H. (2005). Bioreactor design for propagation of somatic embryos. Plant Cell Tiss. Organ Cult. 81, 265-276. doi: 10.1007/s11240-004-6647-0

Hvoslef-Eide, A. K., and Preil, W. (2005). Liquid culture systems for in vitro plant propagation. Dordrecht: Springer Netherlands.

Ibaraki, Y., and Kurata, K. (2001). Automation of somatic embryo production. Plant Cell Tiss. Organ Cult. 65, 179-199. doi: 10.1023/A:1010636525315

Ibraheem, Y., Pinker, I., and Böhme, M. (2013). A comparative study between solid and liquid cultures relative to callus growth and somatic embryo formation in Phoenix dactylifera L. cv. Zaghlool. Emir. J. Food Agric. 25, 883-898. doi: 10.9755/ejfa.v25i11.16661

Ingvarsson, P. K., and Dahlberg, H. (2018). The effects of clonal forestry on genetic diversity in wild and domesticated stands of forest trees. Scand. J. For. Res. 1-10. doi: 10.1080/02827581.2018.1469665. [Epub ahead of print].

Iwata, H., Hayashi, T., and Tsumura, Y. (2011). Prospects for genomic selection in conifer breeding: a simulation study of Cryptomeria japonica. Tree Genet. Genom. 7, 747-758. doi: 10.1007/s11295-011-0371-9

Jamruszka-Lewis, A. M., and Starr, R. A. (2017). Methods of Transferring Plant Embryos to Germination Medium. U.S. Patent No US9572300B2. Washington, DC: U.S. Patent and Trademark Office.

Kim, S. J., Dewir, Y. H., and Moon, H. K. (2011). Large-scale plantlets conversion from cotyledonary somatic embryos of Kalopanax septemlobus tree using bioreactor cultures. J. Plant Biochem. Biotechnol. 20, 241-248. doi: 10.1007/s13562-011-0052-7

Kong, L., Holtz, C. T., Nairn, C. J., Houke, H., Powell, W. A., Baier, K., et al. (2014). Application of airlift bioreactors to accelerate genetic transformation in American chestnut. Plant Cell Tiss. Org. Cult. 117, 39-50. doi: 10.1007/s11240-013-0418-8

Kvaalen, H., and Appelgren, M. (1999). Light quality influences germination, root growth and hypocotyl elongation in somatic embryos but not in seedlings of Norway spruce. In vitro Cell. Dev. Biol. Plant 35, 437-441. doi: 10.1007/s11627-999-0064-3

Lelu-Walter, M.-A., Thompson, D., Harvengt, L., Sanchez, L., Toribio, M., and Pâques, L. E. (2013). Somatic embryogenesis in forestry with a focus on Europe: state-of-the-art, benefits, challenges and future direction. Tree Genet. Genome. 9, 883-899. doi: 10.1007/s11295-013-0620-1

Lindgren, D. (2008). "A way to utilise the advantages of clonal forestry for Norway spruce? ", in: Vegetative Propagation of Conifers for Enhancing Landscaping and Tree Breeding, Proceedings of the Nordic Meeting Held in September 10th-11th 2008 at Punkaharju, Finland, Finnish Forest Research Institute 114: 08-15).

Lu, G., and Fei, B. (2014). Medical hyperspectral imaging: a review. J. Biomed. Opt. 19:010901. doi: 10.1117/1.JBO.19.1.010901

Mallón, R., Covelo, P., and Vieitez, A. M. (2012). Improving secondary embryogenesis in Quercus robur: application of temporary immersion for mass propagation. Trees 26, 731-741. doi: 10.1007/s00468-011-0639-6

Mamun, N. H. A., Aidun, C. K., and Egertsdotter, U. (2018). Improved and synchronized maturation of Norway spruce (Picea abies (L.) H.Karst.) somatic embryos in temporary immersion bioreactors. In vitro Cell. Dev. Biol. Plant 54(Suppl. 6), 612-620. doi: 10.1007/s11627-018-9911-4

Mamun, N. H. A., Egertsdotter, U., and Aidun, C. K. (2015). Bioreactor technology for clonal propagation of plants and metabolite production. Front. Biol. 10, 177-193. doi: 10.1007/s11515-015-1355-1

Marbun, C. L. M., Toruan-Mathius, N., Reflini, Utomo, C., and Liwang, T. (2015). Micropropagation of embryogenic callus of oil palm (Elaeis Guineensis Jacq.) using temporary immersion system. Proced. Chem. 14, 122-129. doi: 10.1016/j.proche.2015.03.018

Mohd, N. M., Ja’afar, H., Zawawi, D. D., and Alias, N. (2017). In vitro Somatic embryos multiplication eurycoma longifolia jack using temporary immersion system RITA (R). Sains Malays. 46, 897-902. doi: 10.17576/jsm-2017-4606-08

Montalbán, I. A., De Diego, N., Aguirre Igartua, E., Setien, A., and Moncaleán, P. (2011). A combined pathway of somatic embryogenesis and organogenesis to regenerate radiata pine plants. Plant Biotechnol. Rep. (2011) 5, 177-186. doi: 10.1007/s11816-011-0171-6
Nehra, N. S., Becwar, M. R., Rottmann, W. H., Pearson, L., Chowdhury, K., Chang, S., et al. (2012). Invited review: forest biotechnology: innovative methods, emerging opportunities. In vitro Cell. Dev. Biol. Plant 41, 701-717. doi: 10.1079/IVP2005691

Niemenak, N., Saare-Surminski, K., Rohsius, C., Ndoumou, D. O., and Lieberei, R. (2008). Regeneration of somatic embryos in Theobroma cacao L. in temporary immersion bioreactor and analyses of free amino acids in different tissues. Plant Cell Rep. 27, 667-676. doi: 10.1007/s00299-007-0497-2

Park, Y.-S., Bonga, J., McCartney, A., and Adams, G. (2014). "Integration of tree biotechnologies into multi-varietal forestry," in Proceedings of the Third International Conference of the IUFRO unit 2.09.02 on Woody Plant Production Integrating Genetic and Vegetative Propagation Technologies, September 8-12, 2014, eds Y.-S.Park, J.M. Bonga (Vitoria-Gasteiz), 95-97.

Perez, M., Bueno, M. A., Escalona, M., Toorop, P., Rodriguez, R., and Canal, M. J. (2013). Temporary immersion systems (RITA) for the improvement of cork oak somatic embryogenic culture proliferation and somatic embryo production. Trees 27, 1277-1284. doi: 10.1007/s00468-013-0876-y

Polonenko, D. R., Voogt, E. V., Eastman, P.,a,.K., and Fan, S. (2005). Process for ex vitro Sowing and Germination of Plant Somatic Embryos. U.S. Patent No US20030061639A1. Washington, DC: U.S. Patent and Trademark Office.

Posada-Pérez, L., Montesinos, Y. P., Guerra, D. G., Daniels, D., and Gómez-Kosky, R. (2017). Complete germination of papaya (Carica papaya L. cv. 'Maradol Roja') somatic embryos using temporary immersion system type RITA ${ }^{\circledR}$ and phloroglucinol in semi-solid culture medium. In vitro Cell. Dev. Biol. Plant 53, 505-513. doi: 10.1007/s11627-017-9842-5

Ptak, A., Simlat, M., Kwiecie,n, M., and Laurain-Mattar, D. (2013). Leucojum aestivum plants propagated in in vitro bioreactor culture and on solid media containing cytokinins. Eng. Life Sci. 13, 261-270. doi: 10.1002/elsc.201200109

Pullman, G. S., Johnson, S., Peter, G., Cairney, J., and Xu, N. (2003). Improving loblolly pine somatic embryo maturation: comparison of somatic and zygotic embryo morphology, germination, and gene expression. Plant Cell Rep. 21, 747-758. doi: 10.1007/s00299-003-0586-9

Rosvall, O., Lindgren, D., and Mullin, T. J. (1998). Sustainability robustness and efficiency of a multi-generation breeding strategy based on within-family clonal selection. Silv. Genet 47, 307-321.

Schapovaloff, J., and Raute, G. (2016). "Operational transfer of genetic improvement in loblolly pine at Arauco Argentina S.A.," in Proc. 4th IUFRO Working party 2.09.02 25-8 September 19-23, 2016, La Plata, Buenos Aires, Argentina.

Sharma, S., Shahzad, A., and Teixeira Da Silva, J. A. (2013). Synseed technology-a complete synthesis. Biotechnol. Adv. 31, 186-207. doi: 10.1016/j.biotechadv.2012.09.007

Shires, M. E., Florez, S. L., Lai, T. S., and Curtis, W. R. (2017). Inducible somatic embryogenesis in Theobroma cacao achieved using the DEXactivatable transcription factor-glucocorticoid receptor fusion. Biotechnol. Lett. 39, 1747-1755. doi: 10.1007/s10529-017-2404-4

Snyman, S. J., Nkwanyana, P. D., and Watt, M. P. (2011). Alleviation of hyperhydricity of sugarcane plantlets produced in RITA ${ }^{\circledR}$ vessels and genotypic and phenotypic characterization of acclimated plants. South Afric. J. Bot. 77, 685-692. doi: 10.1016/j.sajb.2011.03.004

Souza, J. M. M., Tomaz, M. L., Arruda, S. C. C., Demétrio, C. G. B., Venables, W. N., and Martinelli, A. P. (2011). Callus sieving is effective in improving synchronization and frequency of somatic embryogenesis in Citrus sinensis. Biol. Plant. 55, 703-707. doi: 10.1007/s10535-011-0171-y

Steinmacher, D. A., Guerra, M. P., Saare-Surminski, K., and Lieberei, R. (2011). A temporary immersion system improves in vitro regeneration of peach palm through secondary somatic embryogenesis. Ann. Bot. 108, 1463-1475. doi: $10.1093 / \mathrm{aob} / \mathrm{mcr} 033$

Stirn, S., Hopstock, A., and Lörz, H. (1994). Bioreactor cultures of embryogenic suspensions of barley (Hordeum vulgare L.) and maize (Zea mays L.). J. Plant Physiol. 144, 209-214. doi: 10.1016/S0176-1617(11) 80545-6

Sumaryono, Riyadi, I., Kasi, P. D., and Ginting, G. (2008). Growth and differentiation ofembryogenic callus and somatic embryos of oil palm (Elaeis guineensis Jacq.) in temporary immersion system. Indonesian J. Agric. 1, 109-114.

Sun, D., Li, C. Y., Qin, H. Y., Zhang, Q. T., Yang, Y. M., and Ai, J. (2016). Somatic embryos cultures of Vitis amurensis Rupr. in air-lift bioreactors 
for the production of biomass and resveratrol. J. Plant Biol. 59, 427-434. doi: 10.1007/s12374-016-0022-7

Sun, H., Aidun, C. K., and Egertsdotter, U. (2010). Effects from shear stress on morphology and growth of early stages of Norway spruce somatic embryos. Biotechnol. Bioeng. 105, 588-599. doi: 10.1002/bit.22554

Sun, H., Aidun, C. K., and Egertsdotter, U. (2011). Possible effect from shear stress on maturation of Ssmatic embryos of Norway spruce (Picea abies). Biotechnol. Bioeng. 108, 1089-1099. doi: 10.1002/bit.23040

Swanda, A. P. (2015a). Culture harvesting in automated bioreactor system. U.S. Patent Application No US 2015/0093.829 A1. Washington, DC: U.S. Patent and Trademark Office.

Swanda, A. P. (2015b). Gas control in automated bioreactor system. U.S. Patent Application No US 2015/0093741 A1. Washington, DC: U.S. Patent and Trademark Office.

Swanda, A. P., and Givens, H. M. (2017). Systems and methods of separating and singulating embryos. U.S. Patent No US 9,688,953 B2. Washington, DC: U.S. Patent and Trademark Office.

Tapia, E., Sequeida, A., Castro, A., Montes, C., Zamora, P., Lopez, R., et al. (2009). Development of grapevine embryogenesis using an airlift bioreactor as an efficient tool in the generation of transgenic plants. J. Biotechnol. 139, 95-101. doi: 10.1016/j.jbiotec.2008.09.009

Thompson, D. (2013). Development of improved Sitka spruce for Ireland. Irish Forestry. J. 70, 104-118.

Tikkinen, M., Varis, S., and Aronen, T. (2018a). Development of somatic embryo maturation and growing techniques of Norway spruce emblings towards largescale field testing. Forests 9:325. doi: 10.3390/f9060325

Tikkinen, M., Varis, S., Peltola, H., and Aronen, T. (2018b). Improved germination conditions for Norway spruce somatic cotyledonary embryos increased survival and height growth of emblings. Trees 32, 1489-1504. doi: 10.1007/s00468-018-1728-6

Timmis, R., Hirahara, E., Folster, H. G., and Surerus-Lopez, H. (2010). Automated System and Method for Harvesting and Multi-stage screening of Plant Embryos. U.S. Patent No US 7,685,767 B2. Washington, DC: U.S. Patent and Trademark Office.

Timmis, R., and Toland, M. R. (2009). Methods for Processing Spectral Data for Enhanced Embryo Classification. U.S. Patent No US 7,610,155 B2. Washington, DC: U.S. Patent and Trademark Office.

Tonon, G., Berardi, G., Rossi, C., and Bagnaresi, U. (2001). Synchronized somatic embryo development in embryogenic suspensions of Fraxinus angustifolia.
In vitro Cell. Dev. Biol. Plant 37, 462-465. doi: 10.1007/s11627-0010081-3

von Arnold, S., and Clapham, D. (2008). Spruce embryogenesis. Methods Mol. Biol. 427, 31-47 doi: 10.1007/978-1-59745-273-1_3

Von Arnold, S., Sabala, I., Bozhkov, P., Dyachok, J., and Filonova, L. (2002). Developmental pathways of somatic embryogenesis. Plant Cell Tiss. Organ Cult. 69, 233-249. doi: 10.1023/A:1015673200621

Wu, H. X. (2018). Benefits and risks of using clones in forestry - a review. Scand. J. For.Res. doi: 10.1080/02827581.2018.1487579. [Epub ahead of print].

Wu, X., Yang, F., Piao, X. C., Li, K. H., Lian, M. L., and Dai, Y. (2015). High-frequency plantlet regeneration by somatic embryogenesis from mature zygotic embryos of onion. N Z J. Crop Hort. Sci. 43, 249-260. doi: 10.1080/01140671.2015.1049621

Yang, G., Wang, Q., Liu, C., Wang, X., Fan, S., and Huang, W. (2018). Rapid and visual detection of the main chemical compositions in maize seeds based on Raman hyperspectral imaging. Spectrochim. Acta A Mol. Biomol. Spectrosc. 200, 186-194. doi: 10.1016/j.saa.2018.04.026

Yang, J., Zhou, C., Liu, L., Jia, D., Yin, Z., Kim, M., et al. (2012). High conversion frequency of germinated somatic embryos of Siberian ginseng (Eleutherococcus senticosus Maxim) using a bubble column bioreactor. Plant Cell Tiss. Organ Cult. 110, 289-298. doi: 10.1007/s11240-012-0150-9

Yeung, E. C. (1995). "Structural and developmental patterns in somatic embryogenesis," in In vitro Embryogenesis in Plants, eds T. A. Thorpe (Dordrecht: Springer Netherlands), 205-247.

You, X. L., Tan, X., Dai, J. L., Li, Y. H., and Choi, Y. E. (2012). Large-scale somatic embryogenesis and regeneration of Panax notoginseng. Plant Cell Tiss. Org. Cult. 108, 333-338. doi: 10.1007/s11240-011-0030-8

Conflict of Interest Statement: The authors declare that the research was conducted in the absence of any commercial or financial relationships that could be construed as a potential conflict of interest.

Copyright (C) 2019 Egertsdotter, Ahmad and Clapham. This is an open-access article distributed under the terms of the Creative Commons Attribution License (CC BY). The use, distribution or reproduction in other forums is permitted, provided the original author(s) and the copyright owner(s) are credited and that the original publication in this journal is cited, in accordance with accepted academic practice. No use, distribution or reproduction is permitted which does not comply with these terms. 